\title{
Yetişkinlerde Yaşlanma Karşıtı Ürün Kullanımının ve Yaşlanma Kaygısının Değerlendirilmesi
}

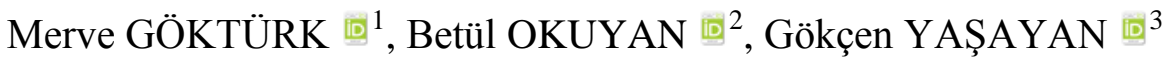

\section{ÖZ}

Amaç: Literatürde yaşlanma karşıtı ürünlerin formülasyonları ve etkinliği hakkında fazla sayıda çalışma olmasına ve bu ürünlerin piyasada yüksek çeşitlilikte bulunmasına karşın, kullanıcıların ürün değerlendirmeleri hakkında yapılan araştırmaların sayısı oldukça azdır. Ayrıca ürün kullanımı ve yaşlanma kaygısı arasındaki ilişki henüz yeterince araştırılmamıştır. Bu çalışma, yetişkinlerin yaşlanma karşıtı ürün kullanımlarının değerlendirilmesi ve yaşlanma kaygılarının belirlenmesi amacıyla gerçekleştirilmiştir.

Gereç ve Yöntemler: Bu tanımlayıcı kesitsel çalışma, herhangi bir sebeple çalışmanın yürütüldüğü İstanbul'da bulunan serbest eczaneyi ziyaret etmiş, çalışmanın amacı ve yöntemi belirtildikten sonra katılmayı kabul eden 18 yaş ve üstü bireylerde yürütülmüştür. Bu kapsamda yaşlanma karșııı ürün kullanımını belirlemek için yapılandırılmış anket ve Yaşlanma Kaygısı Ölçeği katılımcılara uygulanmıştır.

Bulgular: Çalışmaya katılan toplam 106 bireyin yaş ortalaması 32,0土8,7 olarak hesaplanmıştır. Katılımcıların 40'1 yaşlanma karşıtı ürün kullanmamaktadır. Ürün kullanan 66 katılımcının en sık olarak güneşten koruyucu $(\mathrm{n}=41)$, kırışıklık önleyici kremler $(n=30)$ ve göz çevresine uygulanan ürünleri $(n=32)$ tercih ettiği belirlenmiştir. Ürünler çoğunlukla yaşlanma belirtileri görülmeden önce kullanılmaya başlansa da, kullanım devamlılığının oldukça düşük olduğu saptanmıştır. Ürünler hakkında bilgilendirmede internet, ürünleri satın almada ise eczane ve kozmetik marketlerin öncelikli olarak tercih edildiği gözlenmiştir.

Sonuç: Çalışma kapsamında yetişkinlerin yaşlanma karşıtı ürün kullanım sürecindeki motivasyonları ve deneyimleri araştırılmıştır. Yaşlanma Kaygısı Ölçeği ile elde edilen verilere göre, katılımcıların yaşlanma kaygıları ile ne cinsiyetleri ne de ürün kullanımları arasında istatistiksel olarak anlamlı bir ilişki bulunmamıştır.

Anahtar Kelimeler: Eczacı; yaşlanma; yaşlanma karşıtı ürün; yaşlanma kaygısı.

\section{Evaluation of Use of Anti-Aging Products and Aging Concerns in Adults}

\begin{abstract}
Aim: Despite the large number of studies on the formulations and effectiveness of anti-aging products in literature and the high diversity of these products in the market, the number of studies on product evaluation by their users is very low. In addition, the relationship between product use and aging anxiety has not been fully investigated. This study was carried out to evaluate the use of anti-aging products and to determine aging concerns in adults.

Material and Methods: This descriptive cross-sectional study was conducted on individuals aged 18 and over who, for any reason, visited the independent pharmacy in İstanbul where the study was conducted, and agreed to work after the purpose and method of the study has been told. In this context, a structured questionnaire and the Anxiety about Aging Scale were applied to the participants to determine their use of anti-aging products.

Results: The average age of 106 individuals participating to the study was calculated as $32.0 \pm 8.7 .40$ of the participants do not use anti-aging products. It was determined that 66 participants using products preferred to use most frequently sunscreens $(n=41)$, anti-wrinkle creams $(n=30)$ and eye contour products $(n=32)$. Although the products are mostly started to be used before the signs of aging appear, it has been found that the usage continuity is very low. It has been observed that the internet is preferred to be informed on the products, and pharmacy and cosmetic markets are preferred for
\end{abstract}

1 Marmara Üniversitesi, Eczacılık Fakültesi, İstanbul, Türkiye

2 Marmara Üniversitesi, Eczacılık Fakültesi, Klinik Eczacılık Anabilim Dalı, İstanbul, Türkiye

3 Marmara Üniversitesi, Eczacılık Fakültesi, Farmasötik Teknoloji Anabilim Dalı, İstanbul, Türkiye 
purchasing them.

Conclusion: In this study, motivations and experiences of adults during their use of anti-aging products were investigated. According to Anxiety About Aging Scale data, neither the participants gender nor their use of the products were related with the aging anxiety of the participants in terms of statistical significance.

Keywords: Pharmacist; aging; anti-aging products; aging anxiety.

\section{GiRiș}

Yaşlanma, genetik ve çevresel faktörlerin neden olduğu, karmaşık, dinamik, değişken ve çok etmenli bir süreçtir (1-3). Bu süreç içsel ve dişsal faktörlere bağlı olarak değişkenlik göstermektedir (1). İç etmenlere bağlı yaşlanma genetik, endokrin ve metabolik faktörlere bağlı olarak zamanla oluşur. $\mathrm{Bu}$ süreç hücre yenilenmesinin yavaşlaması ile başlayan ve durmasıyla devam eden doğal bir süreçtir. Dişsal yaşlanma ise hava kirliliği, radyasyon, kimyasal maddeler ve güneş 1şı̆̆ gibi çevresel faktörlere ve sigara içme, sağlıksız beslenme, yetersiz uyku, stres gibi yaşam tarzı faktörlerine bağlı olarak oluşur (1,2,4-6). Çevresel faktörlerin en fazla hasar vereni güneş ışınlarıdır ve derideki değişikliklerin $\% 90$ '1ndan sorumludur (2).

Son 200 yıl içerisinde yaşam süresi ve buna bağlı olarak toplumlardaki yaşlı bireylerin oranı istikrarlı olarak artmıştır. Bu konuda yapılan araştırmalar, yaşlanmanın sadece biyolojik değil, aynı zamanda sosyo-kültürel, finansal ve psikolojik etkileri olan bir süreç olduğunu ortaya koymaktadır. Saçların beyazlaması, kırışıklıkların artması gibi yaşlanma belirtilerinin yanı sıra bilişsel ve işlevsel yeteneklerin azalması, kronik hastalıkların artışı, sosyal yalıtım gibi kayıplar nedeniyle bu süreç olumsuz olarak karşılanabilmektedir $(7,8)$.

Günümüzde yaşlılık belirtilerin oluşmasını önlemek ve geciktirmek amacıyla başvurulan yaklaşımlar beslenme, uyku ve fiziksel aktivitenin düzenlenmesi, tıbbi ve cerrahi uygulamalar, kozmetik ürünlerin kullanımı gibi pek çok farklı başlık altında yer almaktadır. Bu amaçla yaşlanma karşıtı ürünler de sıklıkla kullanılmaktadır.

Yaşlanmış ciltte kırışıklık, incelme, sarkma, lekelenmeler, kuruluk görülür. Hücre yenilenmesi azalır, cilt matlaşır ve cilt elastikiyetinde azalma olur $(9,10)$. Yaşlanma karşıtı ürünler, cildin nem kaybını önleyen, deriyi çevresel faktörlerden koruyan, hücre yenileyici bileşenler içeren kozmesötik ürünlerdir. $\mathrm{Bu}$ ürünler, kozmetik ürünlerin fonksiyonlarına ek olarak cildin yaşlanma belirtilerini azaltarak, maskeleyerek veya önleyerek etkisini gösterir ve klasik kozmetiklerden farklı olarak etkinliklerini deri yapı ve fonksiyonlarını etkileyerek gerçekleştirir. Yaşlanma karşıtı olarak sunulan ürünlerin bileşiminde farklı özellikte aktif bileşikler yer almaktadır. Bunlara örnek olarak antioksidanlar, vitaminler, bitki ekstreleri, hidroksi asitler, enzimler, hormonlar, proteinler ve peptidler say1labilir (11-15).

Son yıllarda piyasadaki yaşlanma karşıtı ürünlerin miktarı ve ürün çeşitliliği oldukça artmıştır ve artmaya da devam etmektedir. Buna karşın bireylerin yaşlanma karşı1tı ürün kullanımlarını değerlendiren çalışmaların sayısı oldukça azdır. $\mathrm{Bu}$ çalışma ile bu boşluğun doldurulması amaçlanmıştır. Yaşlanma kaygısı ile ürün kullanımı arasındaki ilişkinin saptanması amacıyla, katılımcıların yaşlanma kaygıları da çalışma kapsamında değerlendirilmiştir.

\section{GEREÇ VE YÖNTEMLER}

$\mathrm{Bu}$ tanımlayıcı kesitsel çalışma, altı ay içerisinde (09.10.2017 - 09.03.2018) İstanbul-Kadıköy'de bulunan ve eczane mesul müdürleri tarafından çalışmaya katılımın kabul edildiği üç serbest eczanede yürütülmüştür. Çalışmada veri toplanması haftanın iki günü (çarşambaperşembe) yapılmıştır. Belirtilen eczaneleri herhangi bir sebeple ziyaret eden, çalışmanın amacı ve yöntemi belirtildikten sonra katılmayı kabul eden 18 yaş ve üstü bireyler çalışmaya dahil edilmiştir. Katılımcılar serbest eczanede kolay ulaşılabilir durum örneklemesi ile belirlenmiştir. Katılımcı seçiminde herhangi bir örneklem hesabı yapılmamıştır; belirtilen süre aralığında kriterlere uygun tüm katılımcılar çalışmaya dahil edilmiştir. Çalışma protokolü, Marmara Üniversitesi Sağlık Bilimleri Enstitüsü Etik Kurulu tarafından onaylanmıştır (Onay tarihi ve onay sayıs1:11.09.2017-173). Katılımcılardan gerekli bilgilendirme sonrası yazılı onam alınmıştır.

Çalışma veri toplaması kapsamında katılımcılardan yüz yüze görüşme yöntemiyle demografik ve klinik (yaş, cinsiyet, eğitim, medeni hal, çalışma durumu, aylık gelir, kronik hastalık, kullanılan ilaç sayısı) bilgiler alınmıştır.

Katılımcıların yaşlanma karşıtı ürünler kullanımı, yapılandırılmış anket sorularıyla değerlendirilmiştir. Öncelikle katılımcılara yaşlanma karşıtı ürün kullanımları sorulmuştur. Ürün kullanmayanlara bunun nedenleri açık uçlu bir soru sorularak belirlenmiştir. Ürün kullananlara ise kullanılan ürünün kategorisi, kullandıkları diğer kozmetik ürünler olup olmadığı ve varsa ne kullandıkları, yaşlanma karşıtı ürün kullanmaya karar verme zamanları, bu ürünleri kullanmaya başlama yaşları ve kullanım süreleri, şu an kullandıkları yaşlanma karşıtı ürünü olup olmadığı, ürünleri kullanmaya nasıl karar verdikleri, ürün tercihlerini belirlemedeki etkenler, yaşlanma karşıtı ürünlerin içeriği hakkında bilgi edinme kaynakları, ürünleri nereden aldıkları, ürün tercihlerini etkileyen faktörler, ürünlerden memnuniyetleri, ürün seçimlerinde fiyatın etkisi, ürün kullanımında karşılaştıkları sorunlar ve sorun yaşadıklarında ne yaptıkları, gebelik ve emzirme döneminde ürün kullanımları sorulmuştur. Ayrıca katılımcılardan kozmetik ürünler konusunda bilgilendirmeleri açısından eczacıları değerlendirmeleri istenmiştir.

\section{Yaşlanma Kaygısı Ölçeği}

Çalışma kapsamında katılımcıların yaşlılık kaygısını değerlendirmek ve yaşlanma karşıtı ürün kullanımının nedenlerini saptamak için katılımcılara Lasher ve Faulkender tarafından geliştirilen Yaşlanma Kaygısı Ölçeği (Anxiety About Aging Scale (AAS)) uygulanmıştır (16).

Uygulanan ölçek yaşlı insanlardan korku, psikolojik çekinceler, fiziksel görünüş ve kayıp korkusu olarak dört alt başlık altındaki konuları değerlendirmektedir. Bu kapsamda yaşlı insanlarla iletişim sonrasında verilen tepkiler (yaşlı insanlardan korku) ile kişinin kendi yaşlanma sürecine (psikolojik çekinceler), fiziksel yaşlılık belirtilerine (fiziksel görünüş), ve yaşlılıkla sahip olduğu bazı yetenekleri kaybetmeye başladığında (kayıp 
korkusu) verdiği tepkiler değerlendirilmiştir (17). Yaşlanma Kaygısı Ölçeği'nin Türkçe versiyonunun geçerliği ve güvenilirliği, Aslı Önol tarafından oluşturulmuştur ve çalışmamızda bu versiyon kullanılmıştır. Ölçekte yüksek skorlar, daha az yaşlılık anksiyetesi olarak yorumlanmıştır (17).

\section{İstatistiksel Analiz}

Tanımlayıcı istatistik analizde bulgular sayı (yüzde), ortalama (standart sapma) ve medyan (çeyrekler arası aralık) olarak sunulmuştur. Çalışmada Kolmogorov Smirnov testi sonucu bulguların parametrik olmayan dağılımı olduğu tespit edilmiştir. İki grup karşılaştırılması için Mann Whitney $U$ testi kullanılmıştır. Ayrıca Spearman korelasyon katsayısı hesaplanmıştır. \%95 güven aralığında $p<0,05$ ise, elde edilen sonuçlar istatistiksel olarak anlamlı olarak tanımlanmıştır. İstatistiksel analizler için SPSS 11.0 kullanılmıştır.

\section{BULGULAR}

\section{Katılımcıların demografik ve klinik özellikleri}

Çalışmanın yürütüldüğü İstanbul'daki eczanelere herhangi bir nedenle gelen 106 kişi, bu çalışmaya katılmayı kabul etmiştir. Katılımcıların demografik ve klinik özellikleri Tablo 1'de sunulmuştur.

Tablo 1. Katılımcıların demografik ve klinik özellikleri $(\mathrm{n}=106)$

\begin{tabular}{|c|c|}
\hline & $\mathrm{n}(\%)$ \\
\hline Yaş ortalama [standart sapma] & $32,0[8,7]$ \\
\hline \multicolumn{2}{|l|}{ Cinsiyet } \\
\hline Kadın & $78(73,6)$ \\
\hline Erkek & $28(26,4)$ \\
\hline \multicolumn{2}{|l|}{ Eğitim } \\
\hline Lisansüstü & $34(32,1)$ \\
\hline Lisans & $60(56,6)$ \\
\hline Lise & $8(7,6)$ \\
\hline Ortaokul & $2(1,9)$ \\
\hline İlkokul & $1(0,9)$ \\
\hline Okur-yazar & $1(0,9)$ \\
\hline \multicolumn{2}{|l|}{ Medeni hal } \\
\hline Evli & $46(43,4)$ \\
\hline Bekar & $60(56,6)$ \\
\hline \multicolumn{2}{|l|}{ Çalıșma Durumu } \\
\hline Evet & $83(78,3)$ \\
\hline Hayır & $23(21,7)$ \\
\hline \multicolumn{2}{|l|}{ Aylık Gelir (n=101) } \\
\hline $1400 €$ ve alt1 & $21(20,8)$ \\
\hline $1401-2500 €$ & $19(18,8)$ \\
\hline $2501-4000 €$ & $28(27,7)$ \\
\hline $4001-6000 €$ & $12(11,9)$ \\
\hline $6001-8000 €$ & $15(14,9)$ \\
\hline $8001-10000 €$ & $5(5,0)$ \\
\hline $10001 €$ ve üstü & $1(1,0)$ \\
\hline Kronik hastalık sayısı & \\
\hline $\begin{array}{l}\text { Medyan } \quad \text { [Çeyrekler } \quad \text { Arası } \\
\text { Aralık] }\end{array}$ & $0[0-1]$ \\
\hline $\begin{array}{l}\text { Toplam kullanılan ilaç/gıda } \\
\text { takviyesi sayısı Medyan } \\
\text { [Çeyrekler Arası Aralık] }\end{array}$ & $0[0-1]$ \\
\hline
\end{tabular}

Çalışmaya katılıp tüm soruları cevaplandıran 106 katılımcının yaş ortalaması $32 \pm 8,7$ olup en düşük yaş 19 , en yüksek yaş ise 58 'dir. Cinsiyete göre dağılımına bakıldığında katılımcıların \%73,6'sının kadın, $\% 26,4$ 'ünün ise erkek olduğu görülmektedir. Eğitim durumu göz önüne alındığında, anketi tamamlayanlar $\% 32,1$ oranında lisansüstü, \%56,6 oranında lisans, \% 7,6 oranında lise, \%1,9 oranında ortaokul, \%0,9 oranında ilkokul mezunu, \%0,9 oranında ise okur-yazardır. Katılımcıların \%43,4'ü evliyken, \%56,6'sı bekardır.

Katılımcıların \%78,3'ü çalıştığını, \%21,7'si ise çalışmadığını belirtmiştir. 5 kişi aylık gelirini belirtmek istememiş, geri kalan 101 katılımcının \%20,8'i aylık gelirini 1400 € ve alt1, \%18,8'i 1401 - 2500 € aras1, $\% 27,7$ 'si 2501 - 4000 ₹ aras1, \%11,9'u 4001 - 6000 € aras1, \%14,9’u $6001-8000$ € aras1, \%5'i 8001 - 10000 € arası, \%1'i 10001 € ve üstü olarak bildirmiştir.

\section{Katılımcıların yaşlanma karşıtı ürün kullanımları}

Çalışmaya katılan 106 kişiye ilk olarak "Yaşlanma karşıtı ürün/ler kullaniyor musunuz?” sorusu sorulmuştur. Katılımcıların \%37,7'sinin (40 kişi) yaşlanma karşıtı ürün kullanmadığı, \%62,3'ünün (66 kişi) ise kullandığı öğrenilmiştir. Ürün kullanmayan 40 katılımcıdan 30 yaş altında olanlar ürün kullanmama nedeni olarak yaşlanma karşıtı ürün kullanmak için erken olmasını, ürünlere gerek görmemeyi, yaşlılıktan korkmamayı, doğanın kanunlarına karşı gelmeyi istememeyi, yaşlanmayı doğal ve gerekli bir evre olarak görmeyi belirtmiştir. 30 yaş ve üstündeki katılımcıların bazıları da ürün kullanmak için henüz erken olduğunu belirtmiştir. Diğerleri ise ürün etkisine inanmadıklarından, çok pahalı olmasından veya ürün toksisitesinden ötürü kullanımı tercih etmediklerini belirtmiştir. $\mathrm{Bu}$ ilk soruya hayır cevabı veren 40 katılımcının anketleri sona erdirilip, çalışmaya geriye kalan 66 katılımcı ile devam edilmiştir.

Ankete devam eden katılımcılara "Kullandığınız ürün hangi kategoride bulunmaktadır?" sorusu sorulmuştur ve 66 katılımcıdan kullandıkları tüm ürün gruplarını bildirmeleri istenmiştir. Katılımcılardan 30 kişi kırışıklık önleyici ürünleri, 9 kişi yaşlılık lekelerini giderici ürünleri, 22 kişi cilt sıkılaştırıcı, cildi gerginleştiren ve elastikiyetini artıran ürünleri, 24 kişi cildi soyan (peeling) ürünleri, 41 kişi UV filtreli güneşten koruyucu ürünleri, 32 kişi göz çevresi ürünleri ve 2 kişi ise diğer ürünleri kullandığını bildirmiştir (Şekil 1). Diğer ürün kategorisindekiler, bitkisel yağ ve fraksiyonel radyo frekans uygulaması olarak bildirilmiştir.

" $\mathrm{Bu}$ ürünlere ek olarak başka kozmetik ürünler de kullanıyor musunuz?" sorusuna katılımciların \%24,2'si hayır cevabı verirken \%75,8'i evet cevabını vermiştir. Soruya "evet" yanıtı veren kişilere hangi ürünleri kullandıkları sorulduğunda, katılımcılardan 34 kişi cilt nemlendiricisi, 33 kişi cilt temizleyicisi, 39 kişi makyaj ürünleri kullandığını söylemiştir.

"Yaşlanma karşıtı ürün kullanmaya ne zaman karar verdiniz?" sorusuna katılımcıların \%66,7'si yaşlılık belirtilerin oluşmasını önlemek ve geciktirmek amacıyla yaşl1lık belirtileri görülmeden önce ürün kullanmaya başladıklarını, \%31,8'i ise belirtileri azaltmak/ilerleyişini engellemek amacıyla yaşlılık belirtilerini gördükten sonra kullanmaya başladıklarını bildirmiştir. Katılımcıların \%1,5'i ise yaşlılık belirtilerinden bağımsız olarak ürün kullanmaya karar verdiğini bildirmiştir. 
Kullandığınız ürün(ler) hangi kategoride bulunmaktadır?

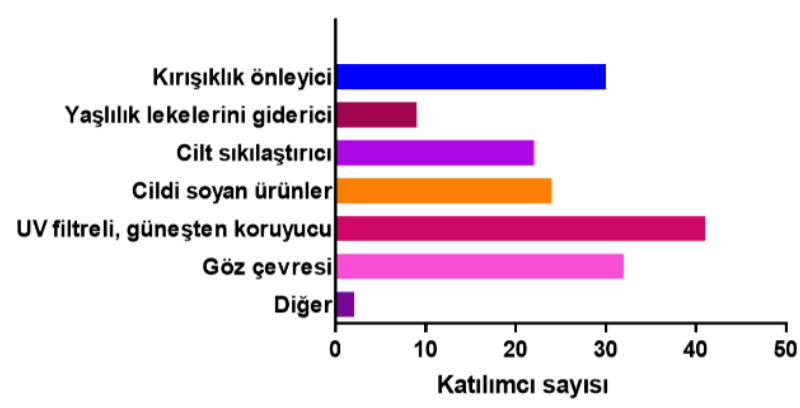

Şekil 1. "Kullandığınız ürün hangi kategoride bulunmaktadır?" sorusuna katılımcıların verdiği yanıtlar.

"Kaç yaşından itibaren yaşlanma karşıtı ürün kullanmaya başladınız?" sorusuna katılımcıların \%28,8'i 20-24 yaş arasında, \%34,8'i 25-29 yaş arasında, \%21,2'si 30-34 yaş arasında, \%9,1'i 35-40 yaş arasında cevabını vermiştir. Katılımcıların \%6,1'i ise anketteki seçeneklerden farklı bir yaş aralığında $(18,45,46$ ve 50 yaş) ürün kullanmaya başladıklarını bildirmiştir.

"Yaşlanma karşıtı ürünleri ne kadar süredir kullanıyorsunuz?" sorusu ile katılımcıların \%36,4'ünün 1 yıldan az süredir, \%30,2'sinin 1-3 y1l arası, \%15,2'sinin 3-5 yıl arası, \%18,2'sinin ise 5 yıldan fazladır yaşlanma karşıtı ürün kullanmakta olduğu tespit edilmiştir. "Mevcut ürününüzü düzenli kullanıyor musunuz?" sorusunu yanıtlayanların \%78,8'i ürünü düzenli kullandığını, \%21,2'si ise ürünü düzenli kullanmadığını bildirmiştir.

"Şu an kullandığınız yaşlanma karşıtı ürün var mı?" sorusuna cevap veren katılımciların \%86,2'si evet yanıtı vermiştir, \%13,8'i hayır demiş, şu an ürün kullanmadığını fakat daha önce kullandığını bildirmiştir.

"Yaşlanma karşıtı ürün kullanmaya nasıl karar verdiniz?" sorusu ile katılımcıların \%6,2'ünün doktor tavsiyesi ile, $\% 20$ 'sinin eczacı tavsiyesi ile, \%13,8'inin güzellik uzmanı tavsiyesi ile, \%27,5'inin yakınının tavsiyesi ile, \%32,5'inin ise internet/gazete gibi kaynaklardan araştırıp kendi kararları ile ürün kullanmaya başladıkları saptanmıştır. "Ürün tercihinizde eczanelerdeki güzellik uzmanları ürün tercihinizde ne derece etkili?" sorusuna katılımcıların \%42,4'ü etkili, \%42,4'ü ne etkili ne etkisiz, $\% 15,2$ 'si ise etkisiz yanıtını vermiştir.

"Yaşlanma karşıtı ürün seçiminde cilt tipinize uygunluğu sizin için ne derece önemlidir?" sorusu ile cilt tipine uygun ürün kullanımının katılımcıların \%95,5'i için önemli, \%3'ü için ne önemli ne önemsiz, \%1,5'i için ise önemsiz olduğu saptanmıştır.

Katılımcılara yönlendirilen "Yaşlanma karşıtı ürünlerin içeriği hakkında bilgi ediniyor musunuz?" sorusu ile katılımcıların \%16,7'sinin ürünün içeriği hakkında bilgi edinmediği saptanmıştır. Bilgi edinenlere nereden bilgi edindikleri sorusuna ise katılımcıların \%69'u internet, $\% 15$ 'i eczane, \%6's1 doktor/dermatolog, \%6's1 ürün temsilcisi, \%4'ü ise ürün ambalajı cevabını vermiştir.

"Ürünü nereden aldınız?" sorusu ile katılımcılardan $\% 46,5$ 'i eczaneleri, \%12,8'i interneti, \%37,2'si kozmetik marketlerini, \%2,3'ü marketi ve \%1.2'si ise diğer mağazaları (natürel ürünler satan mağazalar) tercih ettiğini bildirmiştir. Katılımcıların hiçbiri pazardan ürün almayı tercih etmemektedir.

"Ürün tercihinde dikkat ettiğiniz faktör(ler) nelerdir?" sorusu ile ürün tercihinde katılımcılardan \%6,5'inin ürünün ambalajına, \%30,7'sinin ürünün içeriğine, $\% 13,7$ 'sinin ürünün kokusu ve rengine, \%30,6'sının ürünün markasına, $\% 18,5$ 'inin ise ürünün fiyatına dikkat etmekte olduğu görülmüştür.

"Üründen memnun kaldınız mı?" sorusuna katılımcıların \%71,2'si kullandığı üründen memnun kaldığını, \%3'ü memnun kalmadığını, \%25,8'i ise kararsız kaldığını ifade etmiştir. "Yaşlanma karşıtı ürünlerin fiyatları daha uygun olsaydı farklı bir ürün tercih eder miydiniz?" sorusuna katılımcıların \%60,6'sı farklı bir ürün tercih edeceğini, \%39,4'ü ise tercih etmeyeceğini söylemiştir. "Ürün kullanımında karşılaştığınız sorun oldu mu?" sorulduğunda \%93,9'u bir sorun ile karşılaşmadıklarını, $\% 6,1$ 'i de alerji, cilt kuruluğu, ciltte kıarıklık gibi sorunlar ile karşılaştıklarını bildirmiştir.

"Yaşlanma karşıtı ürünlerle ilgili sorun yaşadığınızda nereye başvuruyorsunuz?" sorulduğunda katılımcıların \%31'i doktora, \%27'si eczacıya, \%14'ü güzellik uzmanına, \%14'ü yakın çevresine, \%9'u marka danışma hattına danışmayı tercih ettiğini bildirmiştir. Geri kalan $\% 5$ 'i ise diğer yollara (Türkiye İlaç ve Tıbbi Cihaz Kurumu (TITCK), internet gibi) başvurduklarını ya da ürün kullanmayı bıraktıklarını söylemiştir.

"Gebelik ve emzirme döneminde ürünleri kullanmaya devam ettiniz mi?" sorusuna katılımciların 34 tanesi yanıt vermiştir. Yanıt verenlerin \%79,4’ü ürünleri kullanmamayı tercih ettiğini veya bu süreçte henüz ürün kullanmaya başlamamış olduğunu, \%20,6's1 ise ürün kullanmaya devam ettiğini bildirmiştir.

"Eczacınızın lisans eğitiminde Kozmetoloji dersini aldığını biliyor musunuz?" sorulduğunda katılımcılardan \%30,3'ünün eczacıların Kozmetoloji dersi aldığını bildiği, \%69,7'sinin ise bilmediği öğrenilmiştir. "Eczacınızın kozmetik ürünler konusundaki bilgisini yeterli buluyor musunuz?" sorusuna katılımciların \%37,9'u yeterli bulduğunu, \%24,2'si yetersiz bulduğunu, \%37,9'u ise kararsız olduğunu belirtmiştir.

\section{Katılımcıların Yaşlanma Kaygıları}

Katılımcıların yaşlanma kaygıları Yaşlanma Kaygısı Ölçeği kullanılarak değerlendirilmiştir ve bulgular Tablo 2'de sunulmuştur.

Yaşlanma Kaygısı Ölçeği’nde katılımcıların en düşük 35 puan, en yüksek 73 puan olmak üzere ortalama puan

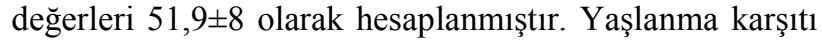
ürün kullanan ve kullanmayan gruplarının yaşlanma kaygısı puan ortalaması arasında istatistiksel olarak anlamlı bir fark tespit edilmemiştir $(p>0,05)$. Puanlamada erkek katılımcıların ortalama puanı 50,6 iken; kadın katılımcıların puanı 52,3 olarak bulunmuştur. Cinsiyetler arasında da istatistiksel olarak anlamlı bir fark tespit edilmemiştir $(p>0,05)$. Kullanılan ilaç sayısı ile yaşlanma kaygısı arasında istatistiksel olarak anlamlı zayıf bir korelasyon tespit edilmiştir $(p<0,05)$.

Tablo 2. Katılımcıların yaşlanma karşıtı ürün kullanımı, cinsiyet ve Spearman korelasyon değerlendirmesine bağlı olarak yaşlanma kaygılarının değerlendirilmesi $(n=106)$ 


\begin{tabular}{|c|c|c|}
\hline $\begin{array}{l}\text { Yaşlanma Karşıtı Ürün } \\
\text { Kullanımı }\end{array}$ & $\begin{array}{c}\text { Yaşlanma } \\
\text { Kaygisı Puanı } \\
\text { Ortalama } \\
\text { [standard hata] }\end{array}$ & $\boldsymbol{P}$ \\
\hline Tüm katılımcılar $(\mathrm{n}=106)$ & $51,9[8,0]$ & - \\
\hline $\begin{array}{l}\text { Yaşlanma Karşıtı } \\
\text { Kullananlar }(\mathrm{n}=66)\end{array}$ & $51,3[1,3]$ & \multirow[t]{2}{*}{0,525} \\
\hline $\begin{array}{l}\text { Yaşlanma Karşıtı Ürün } \\
\text { Kullanmayanlar }(n=40)\end{array}$ & $52,2[1,0]$ & \\
\hline \multicolumn{3}{|l|}{ Cinsiyet } \\
\hline Erkek $(n=28)$ & $50,6[1,4]$ & \multirow[t]{2}{*}{0.484} \\
\hline Kadın $(n=78)$ & $52,3[0,9]$ & \\
\hline $\begin{array}{l}\text { Spearman } \\
\text { KatsayıSı }\end{array}$ & $\begin{array}{c}\text { Yaşlanma Kaygısı } \\
\text { Puanı }\end{array}$ & \\
\hline Yaş & 0,172 & \\
\hline Kronik Hastalık Sayısı & 0,062 & \\
\hline İlaç Sayıs1 & $0,193 *$ & \\
\hline
\end{tabular}

$* p=0,049$

\section{TARTISSMA}

Yaşlılık, dünyaya gelen her canlanın zaman içerisinde kat ettiği mesafe olup, fizyolojik olarak yetişkin bireylerin üreme dönemlerinin bitiminden ölüme kadar geçen dönem olarak tanımlanabilir. Yaşlılık sadece fizyolojik bir süreç olmayıp, toplumsal, kültürel, psikolojik ve sosyo-ekonomik etkileri de olan bir süreçtir $(3,18)$. Bu süreç bazı toplumlarda olgunluk ve bilgelik dönemi olarak kabul görüp olumlu olarak nitelense de, diğgerlerinde sağlık kaybı, fiziksel ve zihinsel kapasitede azalma, başkalarına bağımlılığın artması gibi sebepler nedeniyle olumsuz yargilarla değerlendirilmektedir $(3,19)$. Küresel anlamda ise yaşlılık dönemi üretkenliğin azalması ya da üretimden çekilme, artan kronik hastalıklar ile topluma yük olma ile ilişkilendirilmektedir (20). Yaşlılar da bu süreçten olumsuz olarak etkilenebilmekte, yaşadıkları sorunlara ek olarak kaygı, depresyon gibi psikolojik zorluklarla da baş etmek durumunda kalabilmektedir. Yaşlılık ile eşleştirilen kavramlardan biri de fiziksel çekiciliğin kaybıdır. Medyada sıklıkla "genç ve güzel" olarak betimlenen ideal güzellik algısı, II. Dünya Savaşı sonrasından bu yana etkisini korumakta, bu eşleştirmeye bağlı olarak yaşlılık da güzellik kaybı olarak algılanmaktadır (21).

Son yıllarda gerçekleşen bilimsel ve teknolojik gelişmeler ile yaşam süresi ve kalitesi artmıştır. Yaşlılar eskiye kıyasla daha üretken, dinç ve sağlıklı kalabilmektedir. Kozmetik endüstrisindeki gelişmelere bağlı olarak üretilen yaşlanma karşıtı ürünler ile yaşlılık lekeleri, cilt kırışıklıkları gibi yaşlılığın fizyolojik göstergeleri belli derecelere kadar önlenebilmekte, gizlenebilmekte ya da azaltılabilmektedir.

Son yıllarda ürün grupları yanında ürün pazarlama stratejileri de değişmektedir. Güzellik, yaşlılık ve yaşlılık karşıtı ürünlerin pazarlanması arasındaki ilişkinin ele alındığ bir çalışmada, Isabella Rossellini'nin 42 yaşında güzellik ve feminenliği temsil edemeyecek kadar olgun olması nedeniyle işten kovulduğu 1994 yılından bu yana pazarlama stratejilerinin oldukça değiştiğini vurgulanmaktadır. Bu çalışmada "yaşlandığı halde hala harika görünen" 40 yaş üstü kadınların, yaşlanma karşıtı ürün yüzleri olarak reklamlarda yer aldığ 1 belirtilmiştir (21). Böylece gerek ürün çeşitliliği, gerekse pazarlama stratejileriyle, kullanıcıların medyada sıklıkla betimlenen ideal güzellik algısına yaklaşması hedeflenmekte ve kozmetik ürünlerin yanı sıra yaşlanma karşıtı ürün gruplarının satın alınması ile küresel pazara katkı sağlanmaktadır $(20,22)$.

Piyasada gittikçe artan sayıda yaşlılık karşıtı ürün bulunmasına karşın, kullanıcıların güzellik ve yaşlanma algısı, ürün seçimi ve ürün kullanımları hakkında yapılan araştırmaların sayısı oldukça azdır. Literatürde bu konuda bir çalışmada, doğal ve doğal olmayan yaşlanma, güzellik kavramı ve kozmetik kullanımı arasındaki ilişki araştırılmıştır. 50 ile 70 yaş arasındaki katılımcılar ile gerçekleştirilen çalışmada katılımcılar, doğal yaşlanmayı kırışık karşıtı kremler, saç boyaları, cerrahi ve cerrahi olmayan operasyonlar gibi dış müdahaleler olmadan yaşlanmak olarak tanımlamıştır ve doğal yaşlanmayı övgüye değer bulduklarını belirtmiştir. Buna karşın, katılımcıların çoğunluğu, güzellik uygulamaları yolu ile "doğal bir görünüm” üretmenin önemini dile getirmiştir ve yaşlanmanın fiziksel belirtilerini güzellik uygulamaları kullanılarak savaşılması gereken bir süreç olarak tanımlamıştır (23).

Literatürde başka bir çalışmada, 25 ile 70 yaş arasındaki Fransız kadınların güzellik ve yaşlanma algıları ile minimal invazif kozmetik prosedürlere yaklaşımları araştırılmıştır (6). Bu çalışmada, güzelliğin ana kriterleri doğal görünüm, kendine güven ve çekici bir cilt olarak tanımlanmıştır ve cildin durumu (özellikle cildin pürüzsüzlüğü ve rengi) gençlik, sağlık ve fiziksel çekiciliğin göstergesi olarak değerlendirilmiştir. Ürün kullanımında ana hedefin ise öncelikli olarak yüzdeki yaşl1lık belirtilerinin önlenmesi olarak belirtilmiştir. Genç kadınların yüzdeki yorgun görünüm ve göz çevresindeki halkalardan rahatsız olduğu, daha ileri yaştakilerin ise ince çizgiler, kırışıklıklar ve tonisite kaybından şikayetçi olduğu saptanmıştır. 45 yaş üstündeki kadınlar ek olarak boyun derisindeki gevşemelerden de rahatsız olduklarını bildirmiştir. Katılımcıların cilt nemlendiriciler, güneşten koruyucular başta olmak üzere cildi temizleyen ürünler ve yüze/cilde uygulanan diğer güzellik ürünlerini tercih ettiği saptanmıştır (6).

Çalışmamız kapsamında, İstanbul'daki çalışmanın yürütüldüğü eczanelere gelen katılımcıların hangi ürünleri tercih ettikleri, ürünler hakkında nereden bilgi edindikleri ve bu ürünleri satın almaları altında yatan etmenler gibi parametreler araştırılmıştır. Elde edilen bulgulara göre, yaşlanma karşıtı ürünlerin 106 katılımcıdan 66'sı tarafından satın alındığı saptanmıştır. Fransa'da tercih edilen ürün grupları ile çalışmamızda tercih edilen ürün grupları paralellik göstermektedir (6); çalışmamızdaki katılımcılar da benzer şekilde en fazla güneşten koruyucu ürünlerin tercih etmiş, bunu göz çevresine kullanılan ürünler ve kırışıklık önleyici ürünler takip etmiştir.

Bulgularımıza göre yaşlanma karşıtı ürünler büyük oranda yaşlılık belirtileri görülmeden önce $(\% 66,7)$ kullanılmaya başlanmaktadır. Ürünlerin en sık kullanımı 25 - 29 yaş aralığında olmakla birlikte, $20-24$ yaş aralığında da ürün kullanımının oldukça yüksek olduğu saptanmıştır. Kullanıcıların yaş grupları değerlendirildiğinde, yaşlılık karşıtı ürün kullanıcılarının büyük çoğunluğunun (\%63,6'l1k bir oranla) 30 yaş altı kullanıcılar olduğu görülmektedir. 30 yaşından sonra ürünlerin kullanımı ciddi bir düşüş göstermekte ve kullanıcıların yaşları arttıkça ürün kullanım oranı 
azalmaktadır. Ürün kullanım süreleri ise katılımcı oranı ile ters orantılı olarak değişmektedir; katılımcıların $\% 66,6$ 'lık bir kesimi ürünleri 3 yıldan kısa ürün kullandıklarını belirtmiştir. $\mathrm{Bu}$ bulgu, ankette özellikle yaşlı kitleyi hedef alan yaşlılık lekelerini giderici ürünlerin diğer ürünlere göre daha az kullanılması ile ilişkili bulunmuştur.

Dermatologlar, yaşlanma karşıtı ürünleri ciltte çizgiler, lekelenmeler, kırışmalar gibi yaşlanma belirtileri gözlenmeden önce kullanılmaya başlanmasını ve ürünlerin etkinliği için uzun süreli kullanımı önermektedir (9). Çalışma bulgularında ürün kullanımına erken yaşlarda başlandığı, fakat ortalama ürün kullanım süresinin oldukça kısa olduğu saptanmıştır; bu nedenle kullanıcıların ürünlerin doğru kullanımı konusunda bilgili olmadıkları düşünülmektedir. Erken yaşta ürün kullanımının, gençlerin medyada sıklıkla bahsi geçen güzellik kavramından, reklamlardan, ürün pazarlama stratejilerinden ve belki de fiziksel görünüş ile ilgili sosyokültürel baskılardan diğer yaş gruplarına göre daha fazla etkilenmeleri nedeniyle olabileceği düşünülmektedir. Literatürde medyanın genellikle çocuk ve genç kitleleri hedeflediğine dair pek çok çalışma bulunmaktadır (24). Bu varsayım, ileri araştırmalar ile desteklenmelidir.

Çalışmamızda saptanan erken yaşlarda başlanan kısa süreli ürün kullanımının aksine, Fransa'da gerçekleştirilen çalışmada 35-44 yaş aralığındaki Fransız kadınların \%21'inin ve 45 yaş üstü kadınların \%40'ının ürünleri düzenli kullandığı bildirilmiştir (6). Ayrıca Fransa'daki katılımcılar yaşlanma karşıtı cilt bakımının otuzlu yaşlarının ortasına geldiğinde başlaması gerektiğini bildiklerini ifade etmişlerdir.

Ürün kullanımı ve seçimine etki eden faktörleri değerlendirmek amacıyla sorulan sorularda, kullanıcıların büyük ölçüde internet üzerinden araştırma yaparak ürünleri kendi kararlarıyla ya da yakınlarının tavsiyesiyle kullanmaya başladıkları görülmektedir. Bulgulara göre katılımcıların ürün hakkında bilgi edinmede interneti, fakat ürün satın almada sıklıkla eczane ve kozmetik marketleri tercih etmektedir. Ayrıca katılımcıların büyük kısmı eczacıların kozmetoloji alanında eğitim aldığını bilmemektedir ve katılımcıların sadece \%38'i eczacıların kozmetik ürünler konusundaki bilgisine güvendiğini belirtmiştir. $\mathrm{Bu}$ bulgular eczacıların ürün danışmanlığı konusunda daha aktif olmaları gerektiğini vurgulamaktadır. Yaşlanma karşıtı ürünlerin büyük oranda eczanelerden satın alındığı göz önünde tutulduğunda, eczacıların hem lisans alanındaki bilgi birikimlerini kullanarak, hem de güncel kaynakları takip edip sürekli eğitim programlarına katılarak kozmetik ve dermakozmetik ürünlerin kullanımı ile ilgili etkin bir şekilde danışmanlık hizmeti verebileceği düşünülmektedir.

Ürün tercihinde dikkat edilen faktörler arasında içerik ve marka eşit derecede yüksek puan almıştır. Markaya duyulan güvenin, ürün içeriği kadar yüksek olması, marka değeri yaratmanın ve ürün pazarlama stratejilerinin önemini göstermesi bakımından önemlidir. Katılımcıların \%71,2'si kullandıkları ürünlerden memnun olduğunu ve ürün kullanımında bir sorunla karşılaşmadıklarını $(\% 93,9)$ belirtmesine karşın, \%60,6'lık bir oranla fiyatları daha uygun olduğu takdirde farklı bir ürün tercih edeceğini belirtmiştir. Bu veri de yine ürün tercihinde markanın önemini ve marka değeri ile fiyat arasındaki ilişkiyi vurgulamaktadır.

Literatürdeki çalışmalar, genç görünmek için kadınların üzerindeki baskının erkeklere göre daha fazla olduğunu ve yaşlanma karşıtı ürünlerin hedef kitlesinin genellikle kadınlar olduğunu vurgulamaktadır (22). Bununla beraber son yıllarda ürün kullanan erkek sayısı ve erkekler için olan ürün çeşitliliği hızla artmaktadır (25-27). Bu nedenlerle hem cinsiyete bağlı olarak katılımcıların yaşlanma kaygıları, hem de yaşlılık kaygısı ile yaşlanma karşıtı ürün satın alma ilişkisi Yaşlılık Kaygısı Ölçeği ile değerlendirilmiştir. Yapılan Yaşlanma Kaygısı Ölçeği'nden elde edilen verilere göre katılımcıların yaşlanma kaygıları ile ne cinsiyetleri ne de ürün kullanımları arasında istatistiksel olarak anlamlı bir ilişki bulunmamıştır. Katılımcıların çoğunun henüz yaşlanma belirtilerini göstermemeleri nedeniyle, bulgularda yaşlanma kaygısı ve ürün kullanımı arasında bir bağlantı saptanamadığı düşünülmektedir. Ayrıca bulgulara göre medeni hal ve eğitim durumu ile ürün kullanımı arasında da istatistiksel olarak anlamlı bir ilişki bulunmamıştır.

\section{SONUÇ}

Literatürde yaşlanma karşıtı yaklaşımlar, ürün formülasyonları ve bu yaklaşımların etkinliği konusunda fazla sayıda çalışma bulunmaktadır. Aynı zamanda piyasada da hem fazla sayıda hem de yüksek çeşitlilikte ürün bulunmaktadır. Buna karşın literatürde yaşlanma karşıtı ürün kullanıcıların ürün kullanımını değerlendirmesini içeren araştırmaların sayısı oldukça azdır. $\mathrm{Bu}$ çalışma, yaşlanma karşıtı ürün kullanan katılımcıların ürünleri kullanımı altında yatan nedenlere, kullanım süreçlerine ve ürünleri nasıl seçtiklerine 1 şık tutmak için yapılmıştır. Bu kapsamda katılımcıların yaşlanma kaygısı da değerlendirilmiş, katılımcıların yaşlanma kaygıları ile yaşlanma karşıtı ürün kullanımı arasındaki ilişki saptamaya çalışılmıştır.

Bu çalışmanın sadece Kadıköy'deki üç serbest eczanede gerçekleştirilmiş olması, çalışmanın kısıtlamalarından biridir. Daha sonraki araştırmalar ile ürün kullanımı altında yatan sosyo-kültürel, sosyo-ekonomik, psikolojik nedenleri araştırmak ve çalışmayı daha büyük bir ölçekte gerçekleştirmek hedeflenmektedir. Böylece yaşlanma karşıtı ürün kullanımı ve ürün kullanıcılarının yaklaşımları ile ilgili daha doğru ve kapsamlı verilerin elde edilmesi sağlanacaktır. $\mathrm{Bu}$ çalışmada elde edilen bulguların bu alanda yapılacak diğger araştırmalara olumlu bir katkı sağlamasını umuyoruz.

Yazar katkıları: Fikir/Kavram: M.G., B.O., G.Y.; Tasarım: B.O., G.Y.; Veri Toplama: M.G.; Analiz ve Yorum: M.G., B.O., G.Y.; Literatür Taraması: M.G., G.Y.; Makale Yazımı: M.G., G.Y.; Eleştirel İnceleme: B.O., G.Y.

\section{KAYNAKLAR}

1. Gentilini D, Mari D, Castaldi D, Remondini D, Ogliari G, Ostan R, et al. Role of epigenetics in human aging and longevity: genome-wide DNA methylation profile in centenarians and centenarians' offspring. Age. 2013; 35(5): 1961-73. 
2. Yetkin H, Ceyhan AM, Yıldırım M. Deri yaşlanması ve tedavisi. Medical Journal of Suleyman Demirel University. 2009; 16(2): 32-8.

3. Beğer $T$, Yavuzer $H$. Yaşlilık ve yaşlılık epidemiyolojisi. Klinik Gelişim. 2012; 25(3): 1-3.

4. Chasteen AL, Bashir NY, Gallucci C, Visekruna A. Age and antiaging technique influence reactions to age concealment. Journals of Gerontology Series B: Psychological Sciences and Social Sciences. 2011; 66(6): 719-24.

5. Guinot C, Malvy DJ, Ambroisine L, Latreille J, Mauger E, Tenenhaus M, et al. Relative contribution of intrinsic vs extrinsic factors to skin aging as determined by a validated skin age score. Archives of Dermatology. 2002; 138(11): 1454-60.

6. Ehlinger-Martin A, Cohen-Letessier A, Taieb M, Azoulay E, du Crest D. Women's attitudes to beauty, aging, and the place of cosmetic procedures: insights from the QUEST Observatory. Journal of Cosmetic Dermatology. 2016; 15(1): 89-94.

7. Lavretsky H, Newhouse PA. Stress, inflammation, and aging. The American Journal of Geriatric Psychiatry. 2012; 20(9): 729-33.

8. Chung S. Resistance and acceptance: ambivalent attitudes toward the aging body and antiaging practices among older Korean migrants living in New Zealand. Journal of Women \& Aging. 2020; 32(3): 259-78.

9. Trelles MA. Phototherapy in anti-aging and its photobiologic basics: a new approach to skin rejuvenation. Journal of Cosmetic Dermatology. 2006; 5(1): 87-91.

10. Farage MA, Miller KW, Elsner P, Maibach HI. Characteristics of the aging skin. Advances in Wound Care. 2013; 2(1): 5-10.

11. Chiu A, Kimball AB. Topical vitamins, minerals and botanical ingredients as modulators of environmental and chronological skin damage. British Journal of Dermatology. 2003; 149(4): 681-91.

12. Clarys P, Barel AO. $27 \mathrm{New}$ trends in antiaging cosmetic ingredients and treatments: an overview. Cosmetic Science and Technology. 2009; 1: 291.

13. Yapar EA, Tanrıverdi ST. Yaşlanma karşıtı kozmetik yaklaşımlar ve ürün bileşenleri. Balıkesir Sağlık Bilimleri Dergisi. 2016; 5(2): 99-109.

14. Çelik U, Altunay İK. Yaşlanmayı geciktirici sistemik ve topikal yaklaşımlar. Türkiye Klinikleri Kozmetik Dermatoloji-Özel Konular. 2018; 11(4): 18-24.

15. Yener G. Yaşlanma karşıtı maddeleri taşıyıcı sistemler. Türkiye Klinikleri Kozmetik DermatolojiÖzel Konular. 2017; 10(1): 52-7.

16. Lasher KP, Faulkender PJ. Measurement of aging anxiety: development of the anxiety about aging scale. The International Journal of Aging and Human Development. 1993; 37(4): 247-59.

17. Önol A. Grandparent-grandchild relationships in an aging Turkey: an investigation of intergenerational contact and aging anxiety [Master thesis]. İstanbul: İstanbul Bilgi University; 2013.
18. Bagheri-Nesami M, Shorofi SA. Cultural and socioeconomic factors on changes in aging among Iranian women. Glob J Health Sci. 2014; 6(3): 145-54.

19. Çunkuş N, Yiğitoğlu GT, Akbaş E. Yaşlilık ve toplumsal dışlanma. Geriatrik Bilimler Dergisi. 2019; 2(2): 58-67.

20. Haboush A, Warren CS, Benuto L. Beauty, ethnicity, and age: does internalization of mainstream media ideals influence attitudes towards older adults? Sex Roles. 2012; 66(9-10): 668-76.

21. LaWare MR, Moutsatsos C. "For skin that's us, authentically us": Celebrity, empowerment, and the allure of antiaging advertisements. Women's Studies in Communication. 2013; 36(2): 189-208.

22. Muise A, Desmarais S. Women's perceptions and use of “anti-aging” products. Sex Roles. 2010; 63(1): 12637.

23. Clarke LH, Griffin M. The body natural and the body unnatural: beauty work and aging. Journal of Aging Studies. 2007; 21(3): 187-201.

24. Wadsworth LA, Johnson CP. Mass media and healthy aging. J Nutr Elder. 2008; 27(3-4): 319-31.

25. Halliwell E, Dittmar H. A qualitative investigation of women's and men's body image concerns and their attitudes toward aging. Sex Roles. 2003; 49(11-12): 675-84.

26. Girdwichai N, Chanprapaph K, Vachiramon V. Behaviors and attitudes toward cosmetic treatments among men. The Journal of Clinical and Aesthetic Dermatology. 2018; 11(3): 42.

27. Rieder EA, Mu EW, Brauer JA. Men and cosmetics: social and psychological trends of an emerging demographic. J Drugs Dermatol. 2015; 14(9): 1023-6. 